Journal of Engineering Science and Technology Review 5 (3) (2012) 39 -43

Special Issue on Simulation of Manufacturing Technologies
JOURNAL OF

Engineering Science and

Technology Review

Research Article

\title{
Comparison of the Parallelization Efficiency of a Thermo-Structural Problem Simulated in SIMULIA Abaqus and ANSYS Mechanical
}

\author{
A.M. Yamileva, A.V. Yuldashev and I.Sh. Nasibullayev \\ Ufa State Aviation Technical University, 450000, Russia, Ufa, K.Marx Str., 12
}

Received 1 August 2012; Accepted 25 August 2012

\begin{abstract}
The linear friction welding (LFW) process is characterized by transient nonlinear physical phenomena which result in high stress and temperature gradients in metal objects. To develop an adequate resource efficient numerical model it is necessary to be able to solved with parallel computation for different sets of model parameters. In this paper the parallelization efficiency of a thermo-structural problem is simulated in SIMULIA Abaqus and ANSYS Mechanical and it is compared.
\end{abstract}

Keywords: linear friction welding, engineering software, high-performance computation

\section{Introduction}

Friction welding is a solid state process for joining materials together through frictional contact of a plasticized interface. The appropriate interface condition is generated at the interface by heat produced from frictional contact as one component is moved relative to another under normal pressure. The weld is usually consolidated by a forging force which is applied after the cessation of relative motion. In linear friction welding, the parts move relative to each other in a reciprocating linear mode under friction pressure [1]. LFW is used in aircraft engine manufacturing to connect the blades with disks and getting the so-called blisks in the production of engine compressors.

The high complexity of the finite element simulation is due to the following aspects: Large stresses in the contact area which lead to intensive heat generation and high temperature gradients both of which require a fine-grained mesh for simulation. The process is in effect a coupled (structural and thermal) problem. The transient effects require the use of small $\left(10^{-4} \ldots 10^{-5} \mathrm{~s}\right)$ time steps for the convergence of the computational analysis. Another non linearity of the model arises from the dependence of mechanical and thermo-physical material properties from temperature (physical nonlinearity) and the change of loads and boundary conditions with time (structural nonlinearity) which also need to be taken into account. To perform a number of analyses with different model parameters it is necessary to use multiprocessor systems making it necessary to define the optimal number of parallel threads.

In this work the parallelization efficiency of the thermostructural problem of LFW with the engineering packages SIMULIA Abaqus and ANSYS Mechanical is studied. All

\footnotetext{
* E-mail address: a.yamileva@gmail.com ISSN: 1791-2377 @ 2012 Kavala Institute of Technology. All rights reserved.
}

calculations were performed on the supercomputer of USATU [2].

\section{Computer modeling}

For this work a numerical model was developed in the CAE systems SIMULIA Abaqus and ANSYS Mechanical. The model is for the simulation of the elastic stage of LFW (until flow stress is reached) and it performs a transient analysis and calculates stresses and temperatures in the weldline. This model allows the estimation of the parallelization efficiency of these software packages for a transient coupled-field problem.

In essence this model investigates the thermoelastic deformations of samples due to friction. Geometry consist of two rectangular samples resting on each other with dimensions: $26 \mathrm{~mm} \times 13 \mathrm{~mm} \times 10 \mathrm{~mm}$ for the upper sample (including the clamp zone), $26 \mathrm{~mm} \times 13 \mathrm{~mm} \times 5 \mathrm{~mm}$ for the lower one (Fig. 1).

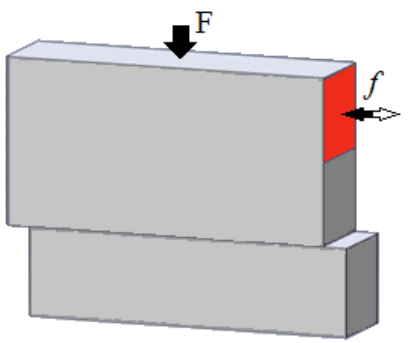

Fig. 1. Geometry of the model

The upper sample oscillates sinusoidaly with a frequency $30 \mathrm{~Hz}$ and an amplitude of oscillation which increases linearly from 0 to $3.8 \mathrm{~mm}$ in $0.1 \mathrm{sec}$. Movement is applied as a boundary condition on the clamp zone nodes (Fig.1 red 
zone). The lower edge of the bottom sample is fixed in space.

A distributed force is applied on the top edge of the upper sample which increases linearly from 15 to $40 \mathrm{kN}$ by a rate of $100 \mathrm{kN} / \mathrm{sec}$. The initial temperature is set to $20^{\circ} \mathrm{C}$. The process is considered to be adiabatic due to the small duration of the process. The material properties of the titanium allow VT6 (an equivalent of Ti-6Al-4V) are used for the material model $[3,4]$.

The friction coefficient is considered as a function of temperature:

$$
\lambda(T)=0,3+5 \cdot 10^{-4}(T-293) .
$$

Modeling results of the temperature and stress fields at the end of elastic stage are shown in Fig. 2.

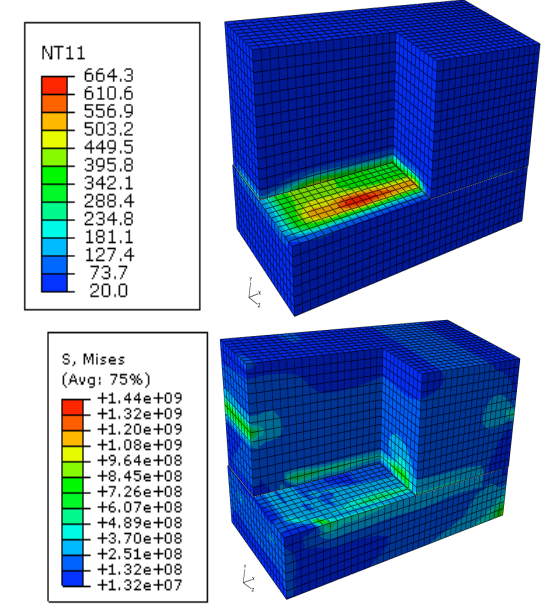

Fig. 2. Temperature field (up, ${ }^{0} \mathrm{C}$ ) and stress field (down, Pa). View of the inside of the upper sample with quarter it hidden for clarity purposes

The calculated temperature field is nonuniform along the contact plane. The maximum heating area appears in the contact plane 3-4 mm from the lateral edges (Fig. 2, on up). The depth of heat penetration at time $0.1 \mathrm{sec}$ into the process is about $2 \mathrm{~mm}$. Maximum stresses arise in the clamping zone (Fig.2, on down), but yielding begins in the weld zone due to heating as von Mises stresses reach $900 \mathrm{MPa}$ in this area.

\section{Parallel computations}

The software packages ANSYS Mechanical 13.0 and 14.0, and SIMULIA Abaqus 6.11 were used. With 25 task licenses of ANSYS Mechanical, which allowed the use of up to 4 cores, and 64 high performance licenses for using addition cores, the maximum that could be reached for one task running is 68 cores. The maximum value of cores per one task that can be used with Abaqus is 32 with the USATU license.

ANSYS allows selecting the solver of equations, and for this task the direct solver of the linear equation systems SPARSE [5] was chosen as the most fast from the asymmetric solvers available. As the amount of RAM is critical for this solver, there were carried no tasks of large equation systems. The MPI-parallelization was used in most of the computations as being more effective than SMP [6].

Abaqus gives a choice of equation system solving schemes between explicit or implicit (Abaqus Explicit or Abaqus Standard), and Abaqus Explicit was used in most cases. The MPI-parallelization was also used.

\subsection{Effect of the finite element size and order on speed of calculations}

The influence of the finite element (FE) size and order (linear and quadratic) was investigated on the parallelization efficiently of this transient problem. Calculations were performed on the supercomputer of USATU using up to 6 nodes: 2 x Intel Xeon $53002.33 \mathrm{GHz}$ (8 cores in node), RAM 8-64 GB, DDRII $667 \mathrm{MHz}$.

Four variants of FE mesh were considered: with linear finite elements of mean size $d=0.7 \mathrm{~mm}, 0.6 \mathrm{~mm}$ and 0.55 $\mathrm{mm}$ and with quadratic finite elements of mean size $\mathrm{d}=0.7$ $\mathrm{mm}$. The parameters of the models are shown in Table 1 .

Table 1. Testing models parameters for different meshes

\begin{tabular}{|c|c|c|c|c|c|c|}
\hline \multirow[t]{2}{*}{ Mesh } & \multicolumn{2}{|c|}{$\begin{array}{l}\text { Number of finite } \\
\text { elements: } \\
\text { volume + contact }\end{array}$} & \multicolumn{2}{|c|}{$\begin{array}{c}\text { Nodes num: volume + } \\
\text { contact }\end{array}$} & \multicolumn{2}{|c|}{$\begin{array}{l}\text { Number of } \\
\text { equations }\end{array}$} \\
\hline & Abaqus & ANSYS & Abaqus & ANSYS & Abaqus & ANSYS \\
\hline $\begin{array}{l}\text { MM, } \\
\text { linear } \\
\text { FE. } \\
d=0.6\end{array}$ & $\begin{array}{c}14763+ \\
2812\end{array}$ & $\begin{array}{c}14763+ \\
1406\end{array}$ & $\begin{array}{c}17480+ \\
8436\end{array}$ & $\begin{array}{l}17480 \\
+0\end{array}$ & 69920 & 67320 \\
\hline $\begin{array}{l}\text { MM, } \\
\text { linear } \\
\text { FE } \\
d=0.55\end{array}$ & $\begin{array}{c}22704+ \\
3784\end{array}$ & $\begin{array}{c}22704+ \\
1992\end{array}$ & $\begin{array}{c}26312+ \\
11352\end{array}$ & $\begin{array}{c}26312 \\
+0\end{array}$ & 105248 & 101798 \\
\hline $\begin{array}{l}\text { MM, } \\
\text { linear } \\
\text { FE } \\
d=0.7\end{array}$ & $\begin{array}{c}30456+ \\
4512\end{array}$ & $\begin{array}{c}30456+ \\
2256\end{array}$ & $\begin{array}{c}34800+ \\
13536\end{array}$ & $\begin{array}{c}34800 \\
+0\end{array}$ & 139200 & 135100 \\
\hline $\begin{array}{l}\text { MM, } \\
\text { quad. } \\
\text { FE }\end{array}$ & $\begin{array}{c}14763+ \\
5624\end{array}$ & $9120+760$ & $\begin{array}{c}67066+ \\
16872\end{array}$ & $\begin{array}{c}42458 \\
+0\end{array}$ & 218678 & 162706 \\
\hline
\end{tabular}

In sequential computations, Abaqus is faster compared to ANSYS, but the difference in computation time decreases with increasing number of equations. With parallelization Abaqus also demonstrates a better computation time in comparison to ANSYS. As shown in Fig. 3, Abaqus reaches saturation on speedup only in the case of the first task; in other cases the task in Abaqus can execute faster with more cores, so speed of large tasks in Abaqus is bounded by the number of licenses for this problem. Using of a larger number of nodes with the same number of cores is preferable as computation of the task is faster.

ANSYS shows smaller maximum of speedup (acceleration of computations with increasing number of processors) in comparison to Abaqus (Table 2). For all tasks in ANSYS the saturation of parallelization is reached for each number of supercomputer nodes tested. The optimal case is with 4 cores on every node.

Table 2. Computation time and RAM usage for transient thermo-structural problem for FE meshes with different characteristics (best result for every task is highlighted)

\begin{tabular}{|c|c|c|c|c|c|c|c|c|}
\hline \multirow[t]{2}{*}{$\begin{array}{c}\text { Mesh } \\
\text { character } \\
\text { istics }\end{array}$} & \multicolumn{2}{|c|}{$\begin{array}{l}\text { Comp. time } \\
\text { (1 core), h. }\end{array}$} & \multicolumn{2}{|c|}{$\begin{array}{l}\text { Min. comp. } \\
\text { time, h. } \\
(\mathrm{N} \times \mathrm{CPN})\end{array}$} & \multicolumn{2}{|c|}{$\begin{array}{c}\text { Uzing RAM } \\
\text { (1x1), Mbyte }\end{array}$} & \multicolumn{2}{|c|}{$\begin{array}{c}\text { Max. RAM on } \\
1 \text { core for case of min. } \\
\text { time, Mbyte }\end{array}$} \\
\hline & $\begin{array}{c}\text { Abaqu } \\
\mathbf{s}\end{array}$ & $\begin{array}{c}\text { ANS } \\
\text { YS }\end{array}$ & $\begin{array}{l}\text { Aba } \\
\text { qus }\end{array}$ & $\begin{array}{c}\text { ANS } \\
\text { YS }\end{array}$ & $\begin{array}{l}\text { Abaq } \\
\text { us }\end{array}$ & $\begin{array}{c}\text { ANSY } \\
\text { S }\end{array}$ & Abaqus & ANSYS \\
\hline $\begin{array}{c}\text { Linear } \\
\text { FE, } \\
\mathrm{d}=0.7 \\
\mathrm{~mm}\end{array}$ & 3.65 & 7.55 & $\begin{array}{c}0.41 \\
(6 \times 4)\end{array}$ & $\begin{array}{c}0.95 \\
(6 \times 6)\end{array}$ & 1405 & 1432 & 471 & 597 \\
\hline $\begin{array}{c}\text { Linear } \\
\text { FE, } \\
\text { d=0.6 } \\
\text { mm }\end{array}$ & 9.38 & $\begin{array}{c}13.8 \\
6\end{array}$ & $\begin{array}{c}0.86 \\
(6 \times 4)\end{array}$ & $\begin{array}{c}1.79 \\
(6 \times 4)\end{array}$ & 2411 & 2505 & 784 & 657 \\
\hline $\begin{array}{c}\text { Linear } \\
\text { FE, } \\
\mathrm{d}=0.55 \\
\mathrm{~mm}\end{array}$ & 18.92 & $\begin{array}{c}19.6 \\
5\end{array}$ & $\begin{array}{c}\mathbf{1 . 6 0} \\
(4 \times 8)\end{array}$ & $\begin{array}{r}2.06 \\
(6 \times 4)\end{array}$ & 3479 & 3621 & 1356 & 699 \\
\hline $\begin{array}{l}\text { Quadrati } \\
\text { c FE, } \\
\mathbf{d = 0 . 7} \\
\mathbf{m m}\end{array}$ & 21.57 & $\begin{array}{c}21.3 \\
5\end{array}$ & $\begin{array}{c}\mathbf{1 . 6 2} \\
(4 \times 8)\end{array}$ & $\begin{array}{c}2.18 \\
(6 \times 6)\end{array}$ & 8277 & 5539 & 3196 & 732 \\
\hline
\end{tabular}
cores number on each node 


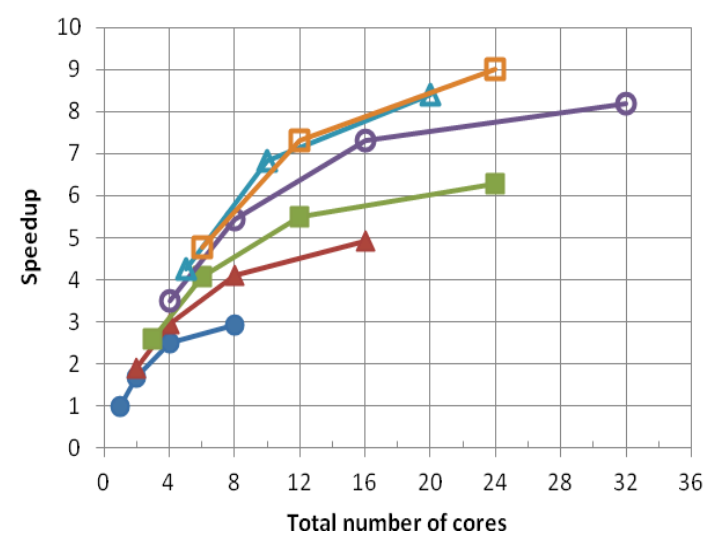

Number of nodes

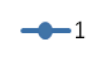

$-2$

$-3$

$-6$

$-5$

$-6$

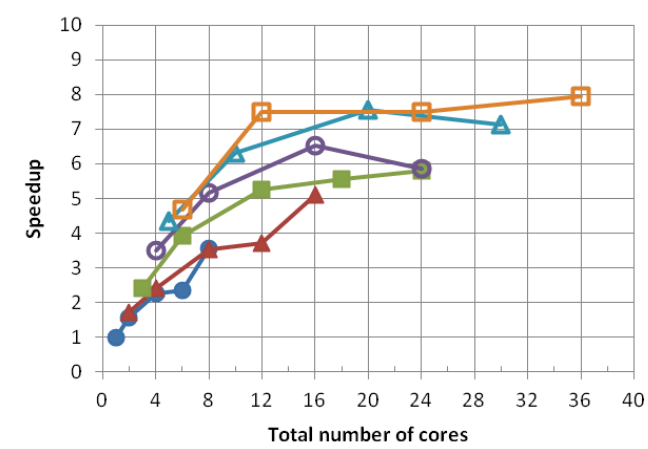

a)
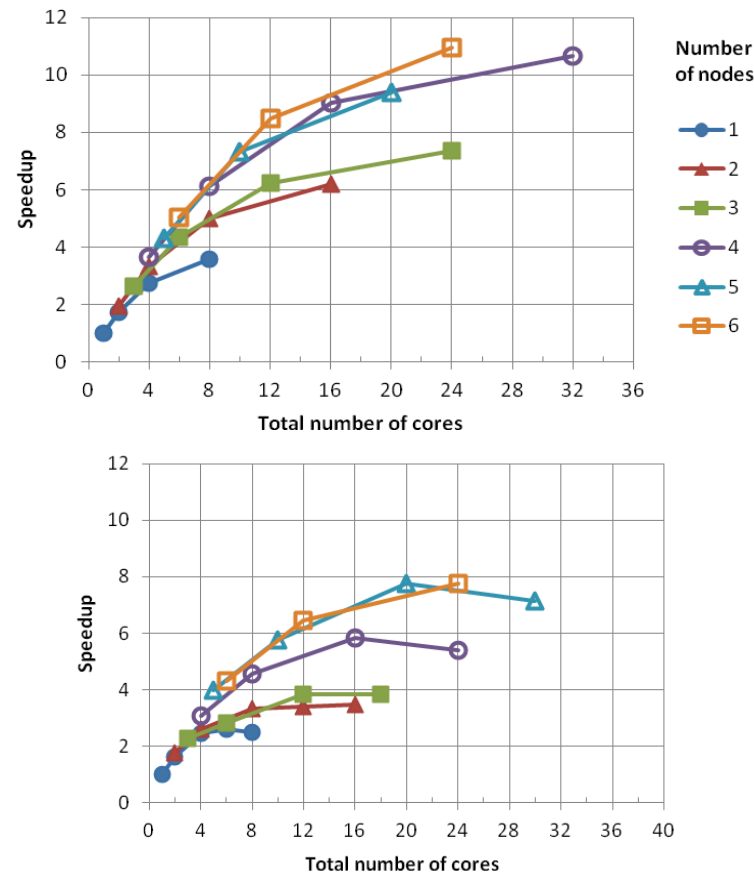

b)

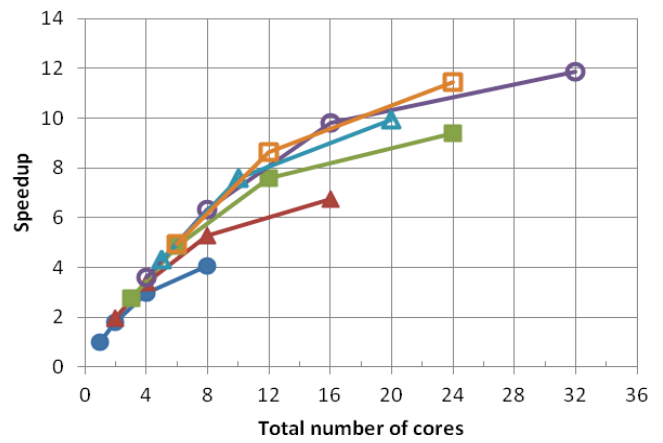

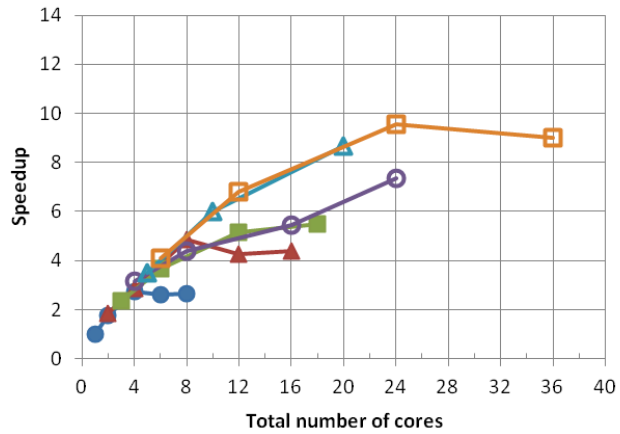

c)
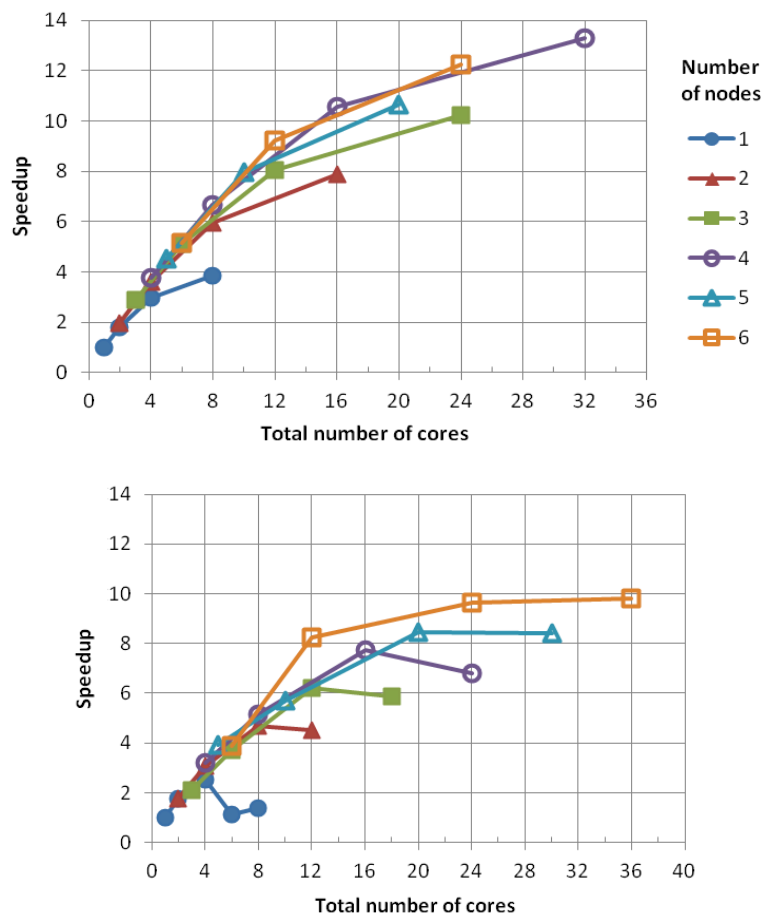

d)

Fig. 3. Speedup relative to computation time $t_{a b}$ and $t_{\text {nn }}$ on 1 core in Abaqus (up) and ANSYS (rdown) consequently: a) using linear FE, $d=$ $0.7 \mathrm{~mm}, \mathrm{t}_{\mathrm{ab}}=3.65 \mathrm{~h}, \mathrm{t}_{\mathrm{an}}=7.55 \mathrm{~h}$

b) using linear FE, $d=0.6 \mathrm{~mm}, \mathrm{t}_{\mathrm{ab}}=9.38 \mathrm{~h}, \mathrm{t}_{\mathrm{an}}=13.87 \mathrm{~h}$

c) using linear FE, $d=0.55 \mathrm{~mm}, \mathrm{t}_{\mathrm{ab}}=18.92 \mathrm{~h}, \mathrm{t}_{\mathrm{an}}=19.65 \mathrm{~h}$

d) using quadratic $\mathrm{FE}, \mathrm{d}=0.7 \mathrm{~mm}, \mathrm{t}_{\mathrm{ab}}=21.57 \mathrm{~h}, \mathrm{t}_{\mathrm{an}}=21,35 \mathrm{~h}$

When quadratic elements were used (Table 1, case 4) in ANSYS the symmetry of geometry was used as RAM on one node is not enough for a full model. In Abaqus the symmetry plane was not used. Therefore, the computation time for both packages is similar when the difficulty of the task is very different. In this case, Abaqus also shows the best result.

It's preferable to use a finer mesh with linear elements, followed by a coarse mesh with quadratic elements for this type of problem, as quadratic elements give better results than linear ones when large deformations are present.

Table 2 show data for the calculations carried out in this research for the transient thermo-structural problem using MPI with up to 6 supercomputer nodes. In most of the tasks faster results were obtained with Abaqus. But on large tasks ANSYS uses less RAM on each core for parallel computations. 


\section{2 GPU acceleration}

The professional graphics processors (GPU) NVIDIA Tesla were recently installed as massively-parallel coprocessors for the acceleration of computations for computer-aided engineer software packages. Among the other software packages that are supported there is ANSYS Mechanical and SIMULIA Abaqus. For the available versions for this work, the support of GPUs was available only for the parallel solvers of these packages using shared memory multiprocessing computer systems (SMP) and was limited to one GPU per simulation.

To study the results of this performance study of thermostructural simulations acceleration using ANSYS Mechanical at IBM iDataPlex dx360M3 a hybrid computing node was installed as part of the university's supercomputer. This node is equipped with two six-core Intel Xeon 5670 central processors and two NVIDIA Tesla M2050 graphics processors. For comparison purposes all simulations were performed with and without GPUs by SMP solvers as GPU acceleration was not supported in MPI solvers.

For the ANSYS simulations three different computer models with different finite elements were used: linear elements of mean size $d=0.6 \mathrm{~mm}$ and $\mathrm{d}=0.55 \mathrm{~mm}$ and quadratic elements with $\mathrm{d}=0.7 \mathrm{~mm}$. The duration of the modeled process was decreased 10 times in order to conduct this performance study in a reasonable amount of time.

As Fig. 4 shows simulation time decreases considerably (1.5-2.5 times) when simulation is performed on the one CPU core with the help of GPU acceleration. The benefit of GPU usage becomes less significant when more CPU cores are used. Also it is clear that higher speedups are observed for models with more elements and linear equations solved during simulation (e.g. mesh 3 at Fig. 4).

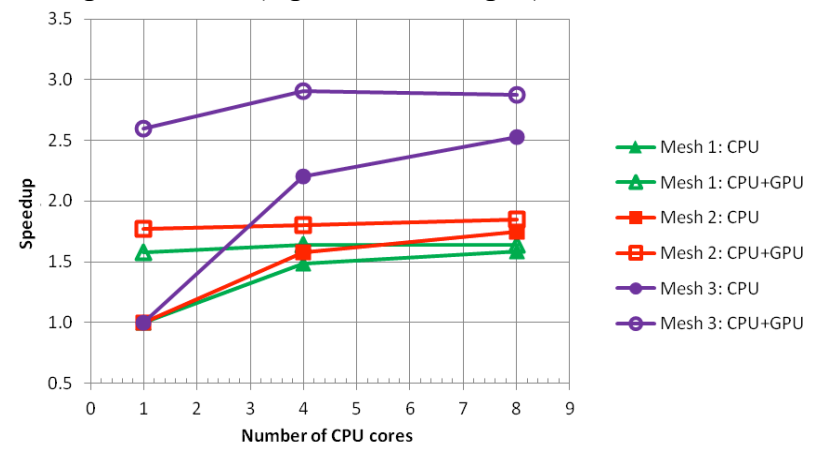

Fig. 4. Speedup relative to computation time $t$ on $1 \mathrm{CPU}$ core in ANSYS: mesh $1-$ linear FE, $d=0.6 \mathrm{~mm}(\mathrm{t}=0.56 \mathrm{~h})$, mesh 2 - linear FE, $d=0.55 \mathrm{~mm}(\mathrm{t}=0.87 \mathrm{~h})$, mesh 3 - quadratic $\mathrm{FE}$, $\mathrm{d}=0.7 \mathrm{~mm}(\mathrm{t}=1.06 \mathrm{~h})$

So when the ANSYS academic version license is used it is possible to decrease simulation time 1.3 times by employing a GPU in addition to 4 CPU cores without using the licenses for parallel computations.

For the Abaqus simulations the numerical model with linear finite elements $(\mathrm{d}=0.7 \mathrm{~mm})$ was used. A symmetric solver was used as GPU acceleration for the asymmetric solver was not supported in Abaqus v. 6.11.

Using GPUs helps to accelerate simulation 1.3 times relative to computation time on one CPU core (Fig. 5). When several (2-8) CPU cores are used the GPU doesn't accelerate simulation significantly due to the small size of the problem which does not benefit form a massivelyparallel GPU architecture.

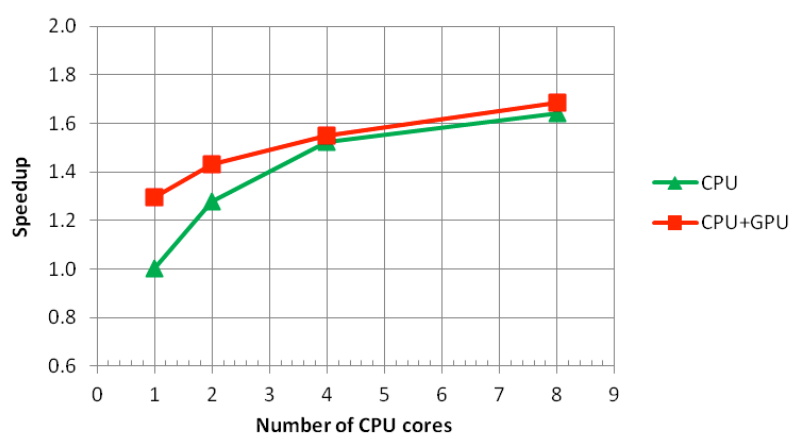

Fig. 5. Speedup relative to computation time on $1 \mathrm{CPU}$ core $(0.58 \mathrm{~h})$ in Abaqus

\section{Conclusions}

The efficiency of parallelization of the SIMULIA Abaqus and ANSYS Mechanical solvers was investigated for the numerical analysis of the LFW process. It was shown, that Abaqus is more efficient when using multicores and multiprocessors computers for this type of problems.

Also the GPU acceleration option that has recently arrived in ANSYS and Abaqus solvers and was investigated as well. It was shown that the usage of GPU as a massivelyparallel coprocessor allows to decrease simulation time significantly when compared to sequential simulations on single CPU core.

\section{Acknowledgements}

This work was produced for the project "The Technology and Manufacturing Production of the Components and Blades of Gas-Turbine Engines with Lightweight HighStrength Constructions for Aircraft Engines of New Generation", supported by the Federal Target Program according to the RF Government Regulation №218 from April, the $9^{\text {th }}, 2010$, "About the measures of State support for development of co-operation of Russian higher education establishments and organizations, realizing the complex projects in developing high-quality production".

\section{Reference}

1. A.Vairis, M.Frost. On the extrusion stage of linear friction welding of Ti6Al4V. Material Science and Engineering, A 271 , 477 (1999).

2. Supercomputer of USATU, high performance computing // Information Technology Management of USATU (in Russian) URL:http://www.ufa-

b.ru/index.php?option $=$ com content $\&$ view $=$ article \&id $=70 \&$ Itemid $=83$ (access date: 19.10 .2012 ).

3. GOST 19807-91: Wrought titanium and titanium alloys. Grades.
Moscow: Standarts Publ., 1991. (in Russian)

4. Characteristic of the material VT6. Database of Steel and Alloys. (in http://www.splav.kharkov.com/mat start.php?name id=1298 (access date: 19.10.2012)

5. ANSYS Mechanical APDL Basic Analysis Guide. Release 13.0. ANSYS Inc., November 2010. [Electronic resource]

6. A.T. Bikmeyev, R.K. Gazizov, V.Yu. Ivanov, A.A. Kasatkin, V.V. 
A.M. Yamileva, A.V. Yuldashev and I.Sh. Nasibullayev

Journal of Engineering Science and Technology Review 5 (3) (2012) 39 -43

Latysh, S.Yu. Lukashchuk, I.Sh. Nasibullayev, K.R. Yulmuhametov, A.M. Yamileva. Analysis of parallelization efficiency of the ANSYS Multiphysics solvers in simulation of linear friction welding // Vestnik of South Ural State University, 25, 64 (in Russian) (2011). 